\title{
Effect of postmenopausal status on insulin sensitivity in myanmar women
}

\author{
Lwin Aye Thet ${ }^{1}$, Mya Thanda Sein ${ }^{2}$, Tint Swe Latt ${ }^{3}$ \\ ${ }^{1}$ Lecturer and Head, Department of Physiology, University of Medical Technology, Yangon, ${ }^{2}$ Professor and Head, \\ Department of Physiology, University of Medicine, Magway, ${ }^{3}$ Rector (Retired), University of Medicine 2, Yangon, \\ Myanmar
}

Background: Animal studies show that ovarian hormone deficiency is associated with development of insulin resistance. In women, the menopause transition marks the cessation of ovarian function and insulin sensitivity would be reduced in postmenopausal women. Aims and Objectives: This study aimed to evaluate the insulin sensitivity in Myanmar postmenopausal women compared to premenopausal women. Materials and Methods: A cross sectional comparative study was undertaken in non obese, normal glucose tolerant post menopausal women ( $\mathrm{n}=42$, BMI (mean \pm SD) $21.3 \pm 2.8 \mathrm{~kg} / \mathrm{m}^{2}$, age $52.6 \pm 4.4$ years) and premenopausal women $\left(\mathrm{n}=33, \mathrm{BMI}\right.$ (mean \pm SD) $19.7 \pm 2.2 \mathrm{~kg} / \mathrm{m}^{2}$, age $32.7 \pm 4.9$ years). Insulin sensitivity was assessed by homeostasis model assessment method of insulin resistance (HOMA-IR) based on fasting blood glucose and fasting serum insulin level. Blood glucose was determined by glucose oxidase method. Serum insulin was estimated by enzyme linked immunosorbent assay (ELISA). Results: No differences in fasting blood glucose level (Mean \pm SD $4.87 \pm 0.51$ vs. $4.76 \pm 0.63 \mathrm{mmol} / \mathrm{L}$ ), fasting serum insulin level [median and interquartile range (IOR) 8.1 (6.7-11.8) vs. 8.1(6.5-9.9) $\mu \mathrm{lU} / \mathrm{ml}$ ] and HOMAIR [median and IQR $1.7(1.4-2.8)$ vs. $1.7(1.2-2.2)]$ were found between premenopausal and postmenopausal women. Conclusion: Postmenopausal status has no effect on insulin sensitivity in postmenopausal women.

Key words: Body mass index (BMI), Fasting blood glucose, Fasting serum insulin, HOMA$\mathrm{IR}$, Postmenopausal women

\section{INTRODUCTION}

Considerable evidences from studies on female rats have showed that ovariectomy decreased insulin-stimulated skeletal muscle glucose uptake. ${ }^{1-3}$ Ovarian hormone deficiency is associated with the development of insulin resistance. Moreover, ovarian hormones may influence glucose uptake by regulating nonoxidative glucose disposal in skeletal muscle. ${ }^{1,4}$ In humans, the menopause transition marks the cessation of ovarian function and dramatic reductions in circulating estrogen and progesterone concentrations. ${ }^{5}$

Accordingly, as ovarian hormone levels are reduced after the menopause transition in women, researchers had hypothesized that postmenopausal state might be associated with reduced insulin sensitivity. In support of this hypothesis, an American study by Lindheim et al., $1994^{6}$ measured the insulin sensitivity by insulin tolerance test in 18 premenopausal women and ten postmenopausal women with Insulin tolerance test and frequently sampled intravenous glucose tolerance test (FSIVGT'T) and observed a reduction in insulin sensitivity in postmenopausal compared to premenopausal women. Similarly, another cross-sectional observation study involving 28 obese premenopausal and 142 postmenopausal Swedish women also found that postmenopausal women are relatively more insulin resistant than premenopausal ones in comparison with same degree of overall obesity. ${ }^{7}$ In this study, insulin sensitivity was measured by IVGTT and EHC methods.

Contrary to this hypothesis, Walton et al., $1993^{8}$ measured insulin sensitivity in 66 premenopausal and 92 postmenopausal 
non-obese Caucasian women with FSIVGTT and reported that measured insulin sensitivity in postmenopausal nonobese Caucasian women was $50 \%$ greater than insulin sensitivity in premenopausal women. On other hand, Toth et al., $2000^{\circ}$ found that there was no change in insulin sensitivity measured by hyperinsulinemic-euglycemic clamp technique between 43 early postmenopausal and 40 premenopausal women from Burlington. A study from North Taiwan ${ }^{10}$ measured insulin sensitivity in 380 premenopausal and 234 postmenopausal women with HOMA-IR and showed no significant difference between them. These conflicting and equivocal findings cannot draw definite conclusion about the effect of postmenopausal status on insulin sensitivity and further confirmation studies are needed. Moreover, evidences from Asian populations are limited. Because of ethnic differences in insulin sensitivity, the findings from Western populations could not be extrapolated directly to Asian population.

Thus, this study was intended to evaluate the effect of postmenopausal status on insulin sensitivity in Myanmar women.

\section{MATERIALS AND METHODS}

\section{Selection of participants}

This was a cross sectional analytical study conducted in the department of Physiology University of Medicine 2, Yangon, Myanmar. Apparently healthy 33 premenopausal women (between 25 and 40 years of aged) and 42 post menopausal women (between 45 and 60 year of age) were recruited in this study. Like previous studies, ${ }^{11-14}$ women with self reported lack of menstruation or spotting for at least 1 year prior to enrolment were classified as post menopausal women. Ethical clearance for conducting the study was obtained from the institutional Ethics committee. Written informed consent was obtained from all subjects. All subjects were examined for a complete medical history taking and physical examination including BMI calculation. Healthy subjects without family history of diabetes, history of chronic smoking and alcohol drinking were included in this study. Then, all participants underwent oral glucose tolerance test (OGTT). After 10-hour overnight fasting, a venous blood sample was taken and then a solution containing $75 \mathrm{gm}$ of glucose anhydrous, in $300 \mathrm{ml}$ of drinking water was given orally. Venous blood was taken again at two hours after the glucose ingestion. Subjects with BMI $>25 \mathrm{~kg} / \mathrm{m}^{2}$, fasting blood glucose $>6.1 \mathrm{mmol} / \mathrm{L}$ and post-prandial blood glucose $>7.8 \mathrm{mmol} / \mathrm{L}$ were excluded from this study.

\section{Blood sample analysis}

Fasting blood sample were taken after fasting for at least 10 hours. $5 \mathrm{ml}$ of venous blood samples were taken an antecubital vein. $1 \mathrm{ml}$ of blood was collected in tube containing $10 \mathrm{mg}$ of sodium fluoride for determination of blood glucose and $4 \mathrm{ml}$ of blood was collected in plain tube for serum separation. Tubes were centrifuged at $3000 \mathrm{xg}$ for 10 minutes. After the collection of blood sample, serum was promptly separated and stored at $\left(-20^{\circ} \mathrm{C}\right)$ until the blood sample analysis.

Fasting blood glucose was measured by glucose oxidase method (Glucose Liquicolor, Human, D-65205 Wiesbaden, Germany) and serum insulin level was measured by Insulin ELISA (DSL-10-1600, Diagnostic System Laboratories, Inc., Texas, USA) kit method. Insulin sensitivity was calculated by following formulas described by Matthews et al. ${ }^{15}$

HOMA-IR $=$ Insulin $(\mu \mathrm{IU} / \mathrm{mL}) \times$ glucose $(\mathrm{mmol} / \mathrm{L}) / 22.5$.

\section{Statistical analysis}

Data were analyzed by using SPSS software for Window (version 16.0, SPSS Inc., Chicago, IL, USA). All data were expressed as mean \pm standard deviation. Skewed data were expressed as median and interquartile range. Difference between those with premenopausal and post-menopausal women were analyzed by using independent two sample $t$-teat or Mann-Whitney U-test, considering it significant at the $\mathrm{p}<0.05$. Statistical analysis of the three sets of data (non-obese premenopausal, non-obese postmenopausal and overweight postmenopausal) for each analysis was carried out by Bonferroni post-hoc test.

\section{RESULTS}

Postmenopausal women were older than premenopausal women significantly $(\mathrm{p}<0.001)$. Postmenopausal women have significantly $(P<0.001)$ more BMI, WC and WHR than premenopausal women. SBP and DBP were significantly higher in the postmenopausal women compared to the premenopausal women (Table 1). FBG. PPBG, fasting serum insulin level and HOMA-IR value were not significantly different between postmenopausal women and the premenopausal women (Table 2).

\section{DISCUSSION}

Present study observed that postmenopausal women have no significant differences in FBG, fasting serum insulin level as compared to premenopausal women. Contrary to this present result, two previous studies ${ }^{16,17}$ reported that mean fasting serum insulin level in postmenopausal women were significantly higher than that in premenopausal women. The postmenopausal women participated in the study of Razay et al., $1992^{16}$ and Poehlman et al., $1995^{18}$ 
Table 1: General characteristic of subjects

\begin{tabular}{lcc} 
Parameters & $\begin{array}{c}\text { Premenopausal } \\
\text { women }(\mathbf{n = 3 3})\end{array}$ & $\begin{array}{c}\text { Postmenopausal } \\
\text { women }(\mathbf{n = 4 2})\end{array}$ \\
\hline Age $($ year $)$ & $32.7 \pm 4.9$ & $52.6 \pm 4.4^{*}$ \\
BMI $\left(\mathrm{kg} / \mathrm{m}^{2}\right)$ & $19.7 \pm 2.2$ & $21.3 \pm 2.8^{*}$ \\
WC $(\mathrm{cm})$ & $75.85 \pm 2.06$ & $77.19 \pm 2.29^{*}$ \\
WHR & $0.8 \pm 0.07$ & $0.86 \pm 0.05^{*}$ \\
SBP $(\mathrm{mmHg})$ & $106.21 \pm 8.93$ & $120.12 \pm 9.03^{*}$ \\
DBP $(\mathrm{mmHg})$ & $68.79 \pm 3.76$ & $76.55 \pm 4.56^{*}$ \\
\hline Significantly different from Premenopausal women $($ P<0.05), *P<0.001. Data \\
presented as mean \pm SD. SD: Standard deviation, BMI: Body mass index, WC: Waist \\
circumference, WHR: Waist hip ratio, SBP: Systolic blood pressure, DBP: Diastolic \\
blood pressure
\end{tabular}

\begin{tabular}{|c|c|c|c|}
\hline Parameters & $\begin{array}{l}\text { Premenopausal } \\
\text { women }(n=33)\end{array}$ & $\begin{array}{l}\text { Postmenopausal } \\
\text { women }(n=42)\end{array}$ & \\
\hline $\mathrm{FBG}(\mathrm{mmol} / \mathrm{L})$ & $4.87 \pm 0.51$ & $4.76 \pm 0.63$ & NS \\
\hline PPBG (mmol/L) & $4.92 \pm 0.94$ & $5.24 \pm 1.11$ & NS \\
\hline Insulin $(\mu \mathrm{IU} / \mathrm{ml})$ & $8.1(6.7-11.8)$ & $8.1(6.5-9.9)$ & NS \\
\hline HOMA-IR & $1.7(1.4-2.8)$ & $1.7(1.2-2.2)$ & NS \\
\hline
\end{tabular}

NS indicates not significant different. Data presented as mean \pm SD for FBG and PPBG; median (IQR) for insulin and HOMA-IR. SD: Standard deviation, IQR: Interquartile range, FBG: fasting blood glucose, PPBG: post-prandial blood glucose, HOMA-IR: homeostasis model assessment - insulin resistance

were associated with higher cholesterol level, higher BMI and higher waist hip ratio. Accordingly hyperinsulinemia is well established feature of obesity; their increased fasting insulin level may be due to increased level of total and intra-abdominal fat. In the present study, BMI and WC were $21.3 \pm 2.8 \mathrm{~kg} / \mathrm{m}^{2}$ and $77.19 \pm 2.29 \mathrm{~cm}$ in all postmenopausal women and $19.7 \pm 2.2 \mathrm{~kg} / \mathrm{m}^{2}$ and $75.85 \pm 2.06 \mathrm{~cm}$ in all premenopausal women (BMI $\left.<25 \mathrm{~kg} / \mathrm{m}^{2}\right)$. They were within normal Asians values (normal BMI range is 18.5 to $22.99 \mathrm{~kg} / \mathrm{m}^{2}$ and WC $<80 \mathrm{~cm}$ ) of BMI and WC for female. Consistent with present study, DeNino et al., $2001^{18}$ recruited the premenopausal women and post menopausal women having normal BMI and WC and showed no significant difference in fasting insulin level between premenopausal women and postmenopausal women.

After statistical analysis of data from the present study and other studies shown in Table 3, the HOMA-IR value of the present study $(1.98 \pm 0.79)$ in the all premenopausal women was relatively comparable with those of previous studies ${ }^{19-22}$ whereas it was found to be significantly lower than that of a study conducted by Akin et al., 2007. ${ }^{23}$ The reason for this discrepancy may be due to higher BMI and WC in premenopausal women participated in that study done by Akin et al., 2007. ${ }^{23}$

Similarly, the HOMA-IR value $(2.52 \pm 2.4)$ of the all postmenopausal women in the present study was relatively comparable with those of studies conducted by Oh et al., 2002:; Kalish et al., 2003, ${ }^{25}$ Cho et al., $20066^{21}$ and Akin et al., $2007^{24}$ whereas it was found to be significantly lower than that of a study conducted by Ahren and Larsson, 2002. ${ }^{26}$

Like previous studies ${ }^{9,23}$ the present study also showed that there was no significant difference between premenopausal and postmenopausal women. Contrary to this, two studies of Lindheim et al., $1994^{6}$ and Nilsson et al., $2000^{27}$ have reported that insulin sensitivity was reduced in post menopausal women. Post menopausal women have increased tendency to be obese with advancing age and more sedentary life style. ${ }^{28,29}$ It was also noted that postmenopausal women recruited in previous studies ${ }^{6,27}$ were associated with increased BMI and central adiposity. Accordingly, HOMA-IR was significantly and positively correlated with BMI and WC..$^{30-32}$ It can be assumed that increased insulin resistance of these postmenopausal women may be due in part to increased BMI and central obesity and did not entirely reflect the effect of menopausal status. Many studies required to evaluate whether decrease in insulin sensitivity after the menopause is related to menopause itself or change in body composition.

On this regard, Toth et al., $2000^{9}$ recruited both premenopausal $(61 \pm 8 \mathrm{~kg})$ and postmenopausal $(66 \pm 9 \mathrm{~kg})$ women having normal body weight and Akin et al., $2007^{23}$ recruited the obese premenopausal (BMI: $35.5 \pm 6.9 \mathrm{~kg} / \mathrm{m}^{2}$, WC: $\left.95.8 \pm 11.7 \mathrm{~cm}\right)$ and postmenopausal women (BMI: $36.2 \pm 6.1 \mathrm{~kg} / \mathrm{m}^{2}$, WC: $\left.96.4 \pm 10.1 \mathrm{~cm}\right)$. In their finding, it was shown that there was no significant difference of insulin sensitivity between premenopausal and postmenopausal women. Similarly, present study intentionally recruited all the non-obese premenopausal and postmenopausal women $\left(\mathrm{BMI}<25 \mathrm{~kg} / \mathrm{m}^{2}\right)$ to reduce the confounding influence of obesity and high level of body fat on insulin sensitivity. In the present study, BMI of postmenopausal women were significantly higher than that of premenopausal women even they are in normal range, If this BMI difference might effect on insulin sensitivity, HOMA-IR value of insulin resistance would be increase in postmenopausal women. However HOMA-IR value was no significantly different between pre- and postmenopausal groups. According to the study of DeNino et al. (2001) ${ }^{18}$, significant reduction in insulin sensitivity was not found until 60 years of age. The postmenopausal women participated in the present study were 45-60 years old. Thus age difference between postmenopausal women (older) and premenopausal women were negligible effect on insulin sensitivity. In the light of the present study, it could be assumed that menopause itself do not affect insulin sensitivity in non-obese postmenopausal women. Previous studies ${ }^{33-35}$ reported that obesity after menopause resulted in insulin 


\begin{tabular}{|c|c|c|c|c|c|c|}
\hline Studies & $\mathbf{N}$ & Age & BMI & WHR & WC & HOMA-IR \\
\hline \multicolumn{7}{|l|}{ Pre-menopausal women } \\
\hline Bonora et al., $2000^{19}$ Italy & 50 & $41.3 \pm 1.4$ & $27.8 \pm 0.7$ & $0.88 \pm 0.01$ & & $2.06 \pm 0.14$ \\
\hline Kang et al., $2005^{20}$ Korea & 22 & $41.6 \pm 12.7$ & $22.5 \pm 5.74$ & $0.9 \pm 0.05$ & & $1.59 \pm 0.86$ \\
\hline Cho et al., $2006^{21}$ UK & 11 & $19-33$ & & & & $1.67 \pm 0.63$ \\
\hline Chang et al., $2006^{22}$ Michigan & 45 & $27 \pm 5$ & $24 \pm 3$ & & & $2.09 \pm 0.14$ \\
\hline Akin et al., $2007^{23}$ Turkey & 151 & $37.2 \pm 9.9$ & $35.5 \pm 6.9$ & & $95.8 \pm 11.7$ & $3.3 \pm 1.71$ \\
\hline Present study, 2009 Myanmar & 33 & $32.73 \pm 4.9$ & $19.75 \pm 2.18$ & $0.8 \pm 0.07$ & $75.85 \pm 2.0$ & $1.98 \pm 0.79$ \\
\hline \multicolumn{7}{|l|}{ Post-menopausal women } \\
\hline Oh et al., $2002^{24}$ California & 216 & $72.4 \pm 6.2$ & $24.2 \pm 3.4$ & $0.8 \pm 0.1$ & $78.8 \pm 8.9$ & $2.6 \pm 1.6$ \\
\hline Ahren et al., $2002^{26}$ Sweden & 81 & 61 & $25.7 \pm 3.4$ & $0.86 \pm 0.05$ & $82.5 \pm 8.8$ & $17.9 \pm 7.8$ \\
\hline Kalish et al., $2003^{25}$ US & 845 & $45-65$ & $17-40$ & $0.59-1.13$ & $61-123$ & $1.7 \pm 1.6$ \\
\hline Cho et al., $2006^{22}$ UK & 11 & $48-70$ & & & & $2.11 \pm 0.79$ \\
\hline Akin et al., $2007^{24}$ Turkey & 76 & $52.8 \pm 5.6$ & $36.2 \pm 6.1$ & & $96.4 \pm 10.1$ & $3.0 \pm 2.0$ \\
\hline Present study, 2009 Myanmar & 42 & $52.62 \pm 4.4$ & $21.3 \pm 2.76$ & $0.86 \pm 0.05$ & $77.19 \pm 2.3$ & $2.52 \pm 2.41$ \\
\hline
\end{tabular}

Data presented as mean \pm SD. SD: Standard deviation, N: Number of subjects, BMI: Body mass index, WHR: Waist hip ratio, WC: Waist circumference, HOMA-IR: homeostasis model assessment - insulin resistance

\begin{tabular}{|c|c|c|c|}
\hline \multirow[t]{2}{*}{ Parameters } & \multicolumn{3}{|c|}{$\mathrm{BMI}<23 \mathrm{~kg} / \mathrm{m}^{2}$} \\
\hline & $\begin{array}{l}\text { Non-obese premenopausal } \\
\text { women }\end{array}$ & $\begin{array}{c}\text { Non-obese postmenopausal } \\
\text { women }\end{array}$ & $\begin{array}{c}\text { Overweight postmenopausal } \\
\text { women }\end{array}$ \\
\hline$n$ & 29 & 23 & 19 \\
\hline FBG (mmol/L) & $4.79 \pm 0.56$ & $4.60 \pm 0.61^{\mathrm{ns}}$ & $4.98 \pm 0.60^{a}$ \\
\hline PPBG (mmol/L) & $4.91 \pm 0.98$ & $5.23 \pm 1.22^{\mathrm{ns}}$ & $5.38 \pm 1.1$ \\
\hline Insulin $(\mu \mathrm{IU} / \mathrm{ml})$ & $6.8(6.7-12.2)$ & $6.8(6.0-9.2)^{\mathrm{ns}}$ & $8.6(7.6-12.3)^{a, b}$ \\
\hline HOMA-IR & $1.76(1.4-3.0)$ & $1.4(1.16-1.8)^{\mathrm{ns}}$ & $2.0(1.58-2.9)^{a, b}$ \\
\hline
\end{tabular}

aSignificant $(\mathrm{P}<0.05)$ difference (by Bonferroni's post-hoc test) between (non-obese postmenopausal and overweight postmenopausal, ${ }^{b}$ non-obese premenopausal and overweight postmenopausal, ns not significant difference $(p>0.05)$ between non-obese premenopausal and non-obese postmenopausal. Data presented as mean \pm SD for FBG and PPBG; median (IQR) for insulin and HOMA-IR. SD: Standard deviation, IQR: Interquartile range, FBG: Fasting blood glucose, PPBG: Post-prandial blood glucose, HOMA-IR: Homeostasis model assessment - insulin resistance

resistance. In the present study, $45 \%$ of postmenopausal women were overweight according to $\mathrm{BMI}>=23 \mathrm{~kg} / \mathrm{m}^{2}$ (Asian people). ${ }^{36}$ The HOMA-IR value of overweight postmenopausal women (19 out of 42 postmenopausal women) was significantly higher than that of non-obese premenopausal (n-29) and postmenopausal women $(n=23)$ (Table 4). Not only obese postmenopausal women but also overweight postmenopausal women resulted in insulin resistance after menopause. So BMI and WC were significant predictors of insulin resistance in post menopausal women. It could be assumed that menopause itself does not affect insulin sensitivity.

\section{CONCLUSION}

This study shows that there was no significant difference of insulin sensitivity between non-obese premenopausal and non-obese postmenopausal women. Observed decrease of insulin sensitivity in overweight postmenopausal women may be due to increased total and intra-abdominal fat. Only hormonal imbalance after menopause does not influence insulin sensitivity. BMI and WC are also strong predictors of insulin resistance. In the light of present study, it could be assumed that menopause itself do not affect insulin sensitivity.

\section{RECOMMENDATION}

Significant reduction in insulin sensitivity was not found until 60 years of age and decreased insulin sensitivity was noted only in more than 60 years old women who were 10-15 years postmenopausal ${ }^{20}$. Physical activity, diet and genetic factor also influence the insulin sensitivity, and insulin sensitivity varies between individuals. So, further longitudinal study is also recommended to examine the change of insulin sensitivity from premenopausal to postmenopausal state in the same individual.

\section{REFERENCES}

1. Puah JA and Bailey CJ. Effect of ovarian hormones on glucose metabolism in mouse soleus muscle. Endocrinology 1985; 
117:1336-1340.

2. Kumagai S, Holmang A and Bjorntorp P. The effects of oestrogen and progesterone on insulin sensitivity in female rats. Acta Physiol Scand 1993; 149:91-97.

3. Rincon J, Holmang A, Wahlstrom EO, Lonnroth P, Bjorntorp P, Zierath JR, et al. Mechanisms behind insulin resistance in rat skeletal muscle after oophorectomy and additional testosterone treatment. Diabetes 1996; 45:615-621.

4. Xie P, Liu ML, Gu YP, Lu J, Xu X and Zeng WM. Oestrogen improves glucose metabolism and insulin signal transduction in HepG2 cells. Clin Exp Pharmcol Physiol 2003; 30(9):643-648.

5. Wich BK and Carnes M. Menopause and the aging female reproductive system. Endocrinol Metab Clin North Am 1995; 24:273-295.

6. Lindheim SR, Buchanan, TA, Duffy DM, Vijod MA, Kojima T, Stanczyk FZ, et al. Comparison of estimates of insulin sensitivity in pre- and postmenopausal women using the insulin tolerance test and the frequently sampled intravenous glucose tolerance test. J Soc Gynecol Investig 1994; 1(2):150-154.

7. Nilsson PM, Lind L, Pollare T, Berne $C$ and Lithell $H$. Differences in insulin sensitivity and risk markers due to gender and age in hypertensives. J Hum Hypertens2000; 14: 51-56.

8. Walton C, Godsland IF, Proudler AJ, Wynn V and Stevenson JC. The effects of the menopause transition on insulin sensitivity, secretion and elimination in non-obese, healthy women. Eur $\mathrm{J}$ Clin Invest 1993; 23:466-473.

9. Toth MJ, Sites CK, Eltabbakh GH and Poehlman ET. Effect of menopausal status on insulin-stimulated glucose disposal. Diabetes Care 2000; 23:801-806.

10. Lin WY, Yaung WS, Lee LT, Chen CY, Liu CS and Lin CC. Insulin resistance, obesity, and metabolic syndrome among nondiabetic pre- and post-menopausal women in North Taiwam. Int J Obesity 2006;30:912-917.

11. Siris ES, Miller PD, Barrett-Connor E, Faulkner KG, Wehren LE and Abbott TA. Identification and Fracture Outcomes of Undiagnosed Low Bone Mineral Density in Postmenopausal Women Results From the National Osteoporosis Risk Assessment FREE. JAMA 2001; 286(22):2815-2822.

12. Wassertheil-Smoller $S$, Hendrix $S$, Limacher M, Heiss $G$, Kooperberg C and Baird A. Effect of Estrogen Plus Progestin on Stroke in Postmenopausal WomenThe Women's Health Initiative: A Randomized Trial FREE. JAMA 2003; 289(20):2673-2684.

13. Hankinson SE, Colditz GA, Willett WC, Michaud DS, Manson JE and Longcope C. Plasma Prolactin Levels and Subsequent Risk of Breast Cancer in Postmenopausal Women. JNCI 1998; 91(7):629-634.

14. Nabholtz JM, Buzdar A, Pollak M, Harwin W, Burton G and Mangalik A. Anastrozole Is Superior to Tamoxifen as FirstLine Therapy for Advanced Breast Cancer in Postmenopausal Women: Results of a North American Multicenter Randomized TriaL JCO 2000;18(22): 3758-3767.

15. Matthews DR, Hosker JP, Rudenski AS, NaylorBA, Treacher DF and Turner R. Homeostasis model assessment: insulin resistance and $\beta$-cell function from fasting plasma glucose and insulin concentrations in man. Diabetologia 1985; 28: 412-419.

16. Razay $\mathrm{G}$, Heaton $\mathrm{KW}$ and Bolton $\mathrm{CH}$. Coronary heart disease risk factors in relation to the menopause. Q J Med 1992; 85: 889-896.

17. Poehlman ET, Tot MJ and Gardner AW. Changes in energy balance and body composition at menopause: A controlled longitudinal study. Ann Intern Med 1995; 123(9):673-575.
18. DeNino WF, Tchernof A, Dionne IJ, Toth MJ, Ades PA, Sites CK, et al. Contribution of abdominal adiposity to age-related differences in insulin sensitivity and plasma lipids in healthy nonobese women. Diabetes Care 2001; 24:925-932.

19. Bonora E, Zavaroni I, Alpi O, Pezzarossa A, Dall'Aglio E, Coscelli $C$, et al. Influence of the menstrual cycle on glucose tolerance and insulin secretion. Am J Obstet Gynecol 1987; 157(1):140-141.

20. Kang ES, Yun YS, Park SW, Kim HJ, Ahn CW, Song YD, et al. Limitation of the validity of the homeostasis model assessment as an index of insulin resistance in Korea. Metabolism 2005; 54:206-211.

21. Cho LW, Jayagopal V, Kilpatrick ES, Jennings $P$ and Atkin SL. Comparison of Insulin Resistance levels in pre and postmenopausal women, women with polycystic ovarian syndrome and postmenopausal women with type 2 diabetes. ECE 2006; 11:716.

22. Chang AM, Smith MJ, Bloem CJ, Galecki AT, Halter JB and Supiano MA. Limitation of the homeostasis model assessment to predict insulin resistance and $\beta$-cell dysfunction in older people. J Clin Endocr Metab 2006; 91:629-634.

23. Akin $F$, Bastemir $M$ and Alkis $E$. Effect of insulin sensitivity on SHBG levels in premenopausal versus postmenopausal obese women. Adv ther 2007; 24(6):1210-1212.

24. Oh JY, Barrett-Connor E, Wedick NM and Wingard DL. Endogenous sex hormones and the development of type 2 diabetes in older men and women: the Rancho Bernardo study. Diabetes Care 2002;25:55-60.

25. Kalish GM, Barrett-Connor E, Laughlin GA and Gulanski BI. Association of endogenous sex hormones and insulin resistance among postmenopausal women: Results from postmenopausal estrogen/progestin intervention trial. J Clin Endocr Metab 2003; 88: 1646-1652.

26. Ahren $B$ and Larsson $H$. Quantification of insulin secretion in relation to insulin sensitivity in nondiabetic postmenopausal women. Diabetes 2002; 52(1):202-211.

27. Nilsson PM, Lind L, Pollare T, Berne $C$ and Lithell $H$. Differences in insulin sensitivity and risk markers due to gender and age in hypertensives. JHum Hypertens 2000; 14:51-56.

28. Lindsay R, Cosman F, Herrington BS and Himmelstein S. Bone mass and body composition in normal women. $\mathrm{J}$ Bone Miner Res 1992; 7: 55-63.

29. Ley CJ, Lee B and Stevenson JC. Sex- and menopause associated changes in body fat distribution. Am J Clin Nutr 1992; 55:950-954.

30. Greco AV, Mingrone G, Giancaterini A, Manco M, Morroni M, Cinti $S$, et al., Insulin resistance in morbid obesity. Diabetes 2002; 51:144-151.

31. Garcia-Estsvez DE, Saavedra- Gonzalez A, Fiestras-Janeiro $G$ and Cabezas-Cerrato J. Analysis of relationship between body mass index, insulin resistance and $\beta$-cell function: A cross sectional study using the minimal model. Metabolism 2004; 53(11):1462-1466.

32. Mya Thanda Sein, Tint Swe Latt and Ohnmar. Insulin Sensitivity and beta cell function in centrally obese male subjects. MMJ 2010; 53(1):16-25.

33. Chu MC, Cosper P, Orio F, Carmina E and Lobo RA. Insulin resistance in postmenopausal women with metabolic syndrome and the measurements of adiponectin, leptin, resistin, and ghrelin. Am J Obstet Gynecol 2005; 194:100-104.

34. Hroussalas G, Kassi E, Dalamaga M, Delimaris I and Zachari A. Leptin, soluble leptin receptor, adiponectin and resistin in relation to OGTT in overweight/obese postmenopausal women. Maturitas 2008; 59:339-349. 
35. Naveed AK, Rajput TA and Mahmood N. Effect of Variations in Body Mass Index on Serum Leptin Levels in Pre and Post Menopausal Women. Glob J of Health Sci 2010; 2(1): 178-192.
36. World Health Organization. The Asia-Pacific perspective; redefining obesity and its treatment. Health communication, Australia. 2000.

\section{Authors Contribution:}

LAT - Conceptualized and executed the study, literature search, collected data and statistically analyzed and interpreted, prepared first draft of manuscript;

MTS - Concept and design of the study, reviewed the literature, statistical analysis and Interpretation of data, participated in drafting, reviewing, and revising

the manuscript for intellectual content; TSL - Concept and design of the study, review of study, critical revision of the manuscript, approved the manuscript to be published.

Source of Support: Nil, Conflict of Interest: None declared. 